\title{
Nature Clinical PARTNERSHIP Rheumatology
}

\author{
Julie Solomon, Jenny Buckland and Peter E Lipsky
}

After only 18 months of publication, the editorial team feels that Nature Clinical Practice Rheumatology is becoming an integral part of the worldwide rheumatology community. We have had the pleasure of working with you as authors, peer reviewers, or general commentators on our progress. We are grateful for the hard work that many of you have invested and for your general interest in the success of the journal. We have also come to appreciate how busy our contributors, peer reviewers, and readers are. Trying to balance treating patients, teaching students, conducting research, managing finances, attending meetings and keeping up with the literature while maintaining a quality lifestyle is not an easy task, especially as the amount of new information continues to grow. By providing you with timely, easy-to-read and authoritative interpretations of key research developments, and translating the latest findings into a form that is relevant to the practice of clinical rheumatology, we hope to save you time plowing through the literature, while keeping you well-informed and up to date.

In this endeavor, however, we rely on input and advice from you (our readers) and members of our Advisory Board. There are three main ways in which practising rheumatologists can help us to achieve our common goal. First, you can write articles on topics you find interesting, which should also be interesting and useful to other rheumatologists. It is through the willing contributions of our authors that we can provide authoritative and objective coverage of the rheumatology literature. Second, you can act as a peer reviewer of those articles. We are sure that many readers would say that their precious time is better spent on other things.
Please send us feedlback ... so that we can keep on improving, and can provide you with the most relevant information on best practice to help improve patient care

J Solomon is Assistant Publisher of the Nature Clinical Practice series of journals. J Buckland is the Editor and PE Lipsky is the Editorin-Chief of Nature Clinical Practice Rheumatology.

Competing interests The authors declared no competing interests.

www.nature.com/clinicalpractice doi:10.1038/ncprheum0482
Peer-reviewing articles, however, gives you the opportunity to act as a quality-control filter, and to ensure that your own expertise is taken into account before an article is published. Your opinions could influence the practice of thousands of rheumatologists worldwide, just like their opinions influence your own. Third, even if you are too busy to accept our invitation to write or peer review, please send us feedback on the journal, on what we are doing well and what we could do better (ncprheum@nature.com), so that we can keep on improving, and can provide you with the most relevant information on best practice to help improve patient care. Also, please try to be available to write or peer review in the future; although we hate to bother you, it is part of our job to persist in seeking the expertise necessary to ensure the excellence of the journal.

Since our launch in November 2005, feedback from the rheumatology community about the journal's content has been remarkably positive. This endorsement would not have been possible without your contributions, whether as readers, peer reviewers, authors, ad hoc commentators or Advisory Board members; please work with us to maintain the high quality of our articles. Help us to evolve in the changing rheumatology landscape and to stay relevant, topical and timely. The next time an editorial office contacts you, be it ours or that of any other journal, please think about the contribution you could make before declining the invitation. Your experience and expertise are vital if we are to achieve our goals: together, we can make a difference to the lives of patients with rheumatic diseases around the world. 